\title{
An observational study of parenteral paracetamol vis a vis tramadol as labour analgesics
}

\section{Pallavi Viswanandh*, Supraja Subramanian, Himadri Bal}

Department of Obstetrics and Gynecology, Dr. D. Y. Patil Medical College, Pimpri, Pune, Maharashtra, India

Received: 15 December 2020

Accepted: 13 January 2021

\author{
*Correspondence: \\ Dr. Pallavi Viswanandh, \\ E-mail: pallavi.1sep@gmail.com
}

Copyright: () the author(s), publisher and licensee Medip Academy. This is an open-access article distributed under the terms of the Creative Commons Attribution Non-Commercial License, which permits unrestricted non-commercial use, distribution, and reproduction in any medium, provided the original work is properly cited.

\begin{abstract}
Background: Labour although a physiological process, is associated with severe, excruciating pain. The delivery of the infant into the arms of a conscious and a pain free mother is one of the most exciting and rewarding moments in medicine .........Moir. Labour analgesia plays an important role in making the process of labour comfortable for the mother. Drugs like paracetamol and tramadol with advantages of easy availability, being inexpensive and with no special technique of administration are a boon for labour analgesia. Our study aims to evaluate the efficacy of these two drugs as labour analgesics.

Methods: Sixty cases in active labour fulfilling inclusion and exclusion criteria were selected for this study. All primigravidae at term gestation with singleton pregnancy having vertex presentation with no associated obstetric/ medical/surgical risk factors in spontaneous labour were selected. There were thirty patients who received Paracetamol as labour analgesic and thirty were in the tramadol group. It was an observational study.

Results: The study revealed that paracetamol had a significant analgesic effect compared to tramadol at the fourth and the fifth hour of administration. However, the overall analgesic effect of both the drugs had no statistically significant difference. Maternal side effects and neonatal distress were less with paracetamol.

Conclusions: This study showed that paracetamol had a better side effect profile for both mother and neonate along with a comparable, if not better, analgesic effect vis a vis tramadol.
\end{abstract}

Keywords: Analgesia, Labour, Pain, Paracetamol, Relief, Tramadol

\section{INTRODUCTION}

Labour pain is a major cause of stress and anxiety which may adversely affect maternal and foetal outcome of labour. ${ }^{1}$ Pain associated sympathetic stimulation can cause maternal hyperventilation, increased oxygen consumption, respiratory alkalosis, and excessive release of catecholamines, uterine vasoconstriction, and decrease in placental blood flow resulting in reduced oxygen transfer to foetus causing metabolic acidosis in the foetus. $^{2}$ Thus, pain relief during labour has shown to improve maternal and perinatal outcome.

An ideal labor analgesic is one that relieves pain, attenuates maternal anxiety and fatigue, does not have any deleterious effect on mother or baby, is easy to administer and requires minimal monitoring. ${ }^{3}$

An array of methods like non-pharmacological techniques, systemic analgesics, regional nerve blocks and epidural analgesia have been used for labour analgesia over the years. Non-pharmacological methods like emotional support, yoga, acupuncture and transcutaneous electrical nerve stimulation (TENS) have not been found to be effective for labor analgesia. ${ }^{4}$ The pharmacological methods include opioids like pethidine, tramadol, fentanyl, morphine, and pentazocine.

Epidural analgesia is generally the analgesic of choice in modern day obstetric practice. ${ }^{5}$ However, in developing countries, majority of obstetric services are in the hands 
of dais, auxiliary nurse cum midwives and nonspecialized doctors. The knowledge and expertise of pain relief during labour and facilities for pain-relief are very limited among these service providers. Hence complex procedures like epidural analgesia is not a universally feasible option in this kind of a scenario. Therefore, drugs like tramadol which are easily available, relatively cheap and also quite safe are a boon for labour analgesia. Tramadol is routinely used in our institution for labour analgesia and paracetamol has been a relatively new inclusion in labour analgesic drug list. We decided to conduct an observational study to objectively compare the efficacy of paracetamol vis a vis tramadol for labor analgesia.

\section{METHODS}

This was an observational study which was conducted at a tertiary care hospital over a period of one year from July 2018-October 2019. Sixty cases in active labour were selected for the study.

\section{Inclusion criteria}

Primigravidae at term gestation in active labour and having singleton pregnancy in vertex presentation with no associated obstetric, medical, surgical morbidities and cervical dilatation $>4 \mathrm{~cm}$ but $<7 \mathrm{~cm}$ with station at -1 and beyond were selected.

\section{Exclusion criteria}

Women with medical disorders like diabetes, hypertension, cardiac disease, severe anaemia; obstetric complications like IUGR, twin pregnancies, abnormal presentation, preterm labour, previous caesarean section or those requiring caesarean section were excluded.

Taking effect size of 0.65 with $80 \%$ power of test at $95 \%$ confidence interval, study sample size came to be 30 in each group using G-power software (version 3.1).

Patients reporting to the labour room satisfying inclusion and exclusion criteria and who received either paracetamol or tramadol as labour analgesic were selected for our study. Written informed consent were obtained from all patients participating in the study.

The patients who were selected for the study were in active labour as mentioned in the inclusion criteria. The criteria considered for active labour were: cervical dilatation of $4 \mathrm{~cm}$ or more; satisfactory uterine activity of 3 contractions lasting for 30 to 40 seconds with moderate to good intensity in a duration of 10 minutes.

Patients were selected in a continuous manner as and when they reported to the labour room. Those satisfying the inclusion and exclusion criteria were selected. Two groups of 30 each were made. Those receiving paracetamol were group $\mathrm{A}$ and those receiving tramadol were group B.

Paracetamol was given in dose of $1000 \mathrm{mg}$ intravenously diluted in $100 \mathrm{ml} \mathrm{NS}$ over 15 minutes and tramadol given in dose of $100 \mathrm{mg}$ tramadol diluted in $100 \mathrm{ml}$ of normal saline given intravenously slowly over 10 minutes.

Before drug administration, intensity of pain sensation was measured on visual analogue scale (VAS) for all participants. Thereafter pain perception was monitored hourly using VAS score for next 6 hours. Measurement of the pain using VAS score was done as follows:

The VAS scores were determined based on self-reported measures of pain by the patient herself which were hand recorded with a mark placed at one point along the length of a $10 \mathrm{~cm}$ line. This line represented a continuum between two ends of the scale with "No pain" on the left end at $0 \mathrm{~cm}$ mark of the scale and the "severe pain" on the right end of the scale at $10 \mathrm{~cm}$ mark. The parturient was asked to self-evaluate and determine the VAS score.

Following cut off points was considered: 0 to $4 \mathrm{~mm}-$ no pain; 5 to $44 \mathrm{~mm}$ - mild pain; 45 to $74 \mathrm{~mm}$ - moderate pain; 75 to $100 \mathrm{~mm}$ - severe pain.

Patients were evaluated for necessity of repeat dose based on pain score. Delivery was conducted as per institutional protocol. APGAR at 1 minute and 5 minutes and any evidence of respiratory distress were noted from case files. Similarly, patient and neonatal follow up for first 24 hours post-delivery were also recorded from the case files.

Relevant history including available previous records and general, physical and obstetric examination findings of all the participants were obtained from the documents. Admission test of all labour cases are routinely performed in our institution.

The data was statistically analysed. Data was entered in EXCEL and analysed using Epi 7/WinPepi/SPSS. Quantitative data was summarized using mean and SD. Qualitative data was summarized using proportions. Tests of statistical significance such as Chi square, $\mathrm{T}$ test and paired $\mathrm{T}$ test were used.

Ethical clearance was obtained for the study from the Institutional Ethical Committee.

\section{RESULTS}

The patient profile in both the groups were evenly matched. The majority of patients in both the groups were in the age bracket of 21-25 years (Table 1).

Most of the parturient in both groups were between 39 and 40 weeks of gestational age (Table 2). 
Table 1: Distribution of cases according to age of parturient.

\begin{tabular}{|llll|}
\hline $\begin{array}{l}\text { Age group } \\
\text { (years) }\end{array}$ & $\begin{array}{l}\text { Analgesic }(\%) \\
\text { Paracetamol }\end{array}$ & Tramadol & Total $(\%)$ \\
\hline $\mathbf{1 8 - 2 0}$ & $7(23.3)$ & $6(20.0)$ & $13(21.7)$ \\
\hline $\mathbf{2 1 - 2 5}$ & $16(53.3)$ & $16(53.3)$ & $32(53.3)$ \\
\hline $\mathbf{2 6 - 3 0}$ & $7(23.3)$ & $8(26.7)$ & $15(25.0)$ \\
\hline Total & $30(100.0)$ & $30(100.0)$ & $60(100.0)$ \\
\hline P value 0.93 & & & \\
\hline
\end{tabular}

Table 2: Distribution of cases according to gestational age on admission.

\begin{tabular}{|c|c|c|c|}
\hline \multirow{2}{*}{$\begin{array}{l}\text { Gestational } \\
\text { age (weeks) }\end{array}$} & \multicolumn{2}{|c|}{ Analgesic (\%) } & \multirow{2}{*}{ Total (\%) } \\
\hline & Paracetamol & Tramadol & \\
\hline 37.0-37.9 & $3(10.0)$ & $3(10.0)$ & $6(10.0)$ \\
\hline 38.0-38.9 & $12(40.0)$ & $6(20.0)$ & $18(30.0)$ \\
\hline 39.0-39.9 & $10(33.3)$ & $17(56.7)$ & $27(45.0)$ \\
\hline $40.0-40.9$ & $5(16.7)$ & $3(10.0)$ & $8(13.3)$ \\
\hline 41-41.9 & 0 & $1(3.3)$ & $1(1.7)$ \\
\hline Total & $30(100.0)$ & $30(100.0)$ & $60(100.0)$ \\
\hline
\end{tabular}

With majority of the cases having cervical dilatation of 4 $\mathrm{cm}$ (Table 3) and effacement of 60 to $80 \%$ (Table 4).

Table 3: Distribution of cases according to cervical dilatation at admission.

\begin{tabular}{|llll|}
\hline $\begin{array}{l}\text { Cervical } \\
\text { dilatation } \\
(\mathbf{c m})\end{array}$ & \multicolumn{2}{l}{ Analgesic (\%) } & Total $(\%)$ \\
\hline $\mathbf{4}$ & $12(40.0)$ & $12(40.0)$ & $24(40.0)$ \\
\hline $\mathbf{5}$ & $11(36.7)$ & $10(33.3)$ & $21(35.0)$ \\
\hline $\mathbf{6}$ & $7(23.3)$ & $8(26.7)$ & $15(25.0)$ \\
\hline Total & $30(100.0)$ & $30(100.0)$ & $60(100.0)$ \\
\hline
\end{tabular}

$\mathrm{P}$ value 0.94

Table 4: Distribution of cases according to cervical effacement on admission.

\begin{tabular}{|llll|}
\hline $\begin{array}{l}\text { Cervical } \\
\text { effacement on } \\
\text { admission }\end{array}$ & \multicolumn{2}{l}{ Analgesic (\%) } & Total (\%) \\
\cline { 1 - 4 } $\mathbf{6 0 - 7 0} \%$ & $13(43.3)$ & $14(46.7)$ & $27(45.0)$ \\
\hline $\mathbf{7 0 - 8 0} \%$ & $15(50.0)$ & $12(40.0)$ & $27(45.0)$ \\
\hline $\mathbf{8 0 \%}$ or more & $2(6.7)$ & $4(13.3)$ & $6(10.0)$ \\
\hline Total & $30(100.0)$ & $30(100.0)$ & $60(100.0)$ \\
\hline P value 0.59 & & & \\
\hline
\end{tabular}

Mean duration of labour in paracetamol group $(6.37 \pm 1.65$ hours) was found to be marginally more than the tramadol group (5.97 \pm 1.48 hours) (Table 5). Association between duration of labour among both groups was statistically insignificant. It was also observed that none of the patients among either groups required repeat dose of analgesic.
Table 5: Comparison of duration of labour in paracetamol and tramadol group.

\begin{tabular}{|lllll|}
\hline Variable & Analgesic & N & Mean & SD \\
\hline Duration of & Paracetamol & 30 & 6.37 & 1.65 \\
\cline { 2 - 5 } labour (hours) & Tramadol & 30 & 5.97 & 1.48 \\
\hline P value 0.39 & & & &
\end{tabular}

Mean VAS score on admission in Paracetamol group was $7.63 \pm 1.351$ and tramadol group was 7.90 \pm 1.094 . Differences in VAS score between the groups at 1, 2, 3 and 6 hours were statistically insignificant. However at 4 and 5 hours of active labour, paracetamol showed statistically significant more pain relief as compared to tramadol (Table 6) ( $\mathrm{p}$ value at $4^{\text {th }}$ hour 0.001 and $\mathrm{p}$ value at $5^{\text {th }}$ hour 0.01$)$.

Table 6: Distribution of cases according to VAS score.

\begin{tabular}{|c|c|c|c|c|}
\hline Variable & Analgesic & $\mathbf{N}$ & Mean \pm SD & P value \\
\hline \multirow{2}{*}{$\begin{array}{l}\text { VAS on } \\
\text { Admission }\end{array}$} & Paracetamol & 30 & $7.63 \pm 1.351$ & \multirow{2}{*}{0.39} \\
\hline & Tramadol & 30 & $7.90 \pm 1.094$ & \\
\hline \multirow{2}{*}{ VAS at 1 hour } & Paracetamol & 30 & $6.60 \pm 1.380$ & \multirow{2}{*}{0.22} \\
\hline & Tramadol & 30 & $7.03 \pm 1.326$ & \\
\hline \multirow{2}{*}{ VAS at 2 hours } & Paracetamol & 30 & $6.87 \pm 1.383$ & \multirow{2}{*}{0.22} \\
\hline & Tramadol & 30 & $7.30 \pm 1.317$ & \\
\hline \multirow{2}{*}{ VAS at 3 hours } & Paracetamol & $29 *$ & $7.31 \pm 1.072$ & \multirow{2}{*}{0.12} \\
\hline & Tramadol & 30 & $7.77 \pm 1.194$ & \\
\hline \multirow{2}{*}{ VAS at 4 hours } & Paracetamol & $28 *$ & $7.64 \pm 1.096$ & \multirow{2}{*}{0.00} \\
\hline & Tramadol & $29 *$ & $8.48 \pm 1.090$ & \\
\hline \multirow{2}{*}{ VAS at 5 hours } & Paracetamol & $21 *$ & $7.86 \pm 1.014$ & \multirow{2}{*}{0.0} \\
\hline & Tramadol & $26^{*}$ & $8.62 \pm 1.134$ & \\
\hline \multirow{2}{*}{ VAS at 6 hours } & Paracetamol & $11^{*}$ & $8.55 \pm 0.934$ & \multirow{2}{*}{0.9} \\
\hline & Tramadol & $16^{*}$ & $8.50 \pm 1.317$ & \\
\hline
\end{tabular}

Reduced numbers of cases at 3, 4, 5, 6 hours denoted by $*$ represents the cases that have already delivered.

Analysis of APGAR score showed that among the paracetamol group, $20 \%$ babies had neonatal distress whereas in the tramadol group $30 \%$ babies had distress and the association was found to be statistically insignificant.

The incidence of nausea and vomiting, observed within 30 minutes of administration of the drug was more with tramadol as compared to paracetamol and this difference was found to be statistically significant ( $p$ value- 0.01 )

\section{DISCUSSION}

Labour pains are a major cause of stress and anxiety for the parturient mother and this adversely affects both maternal and foetal outcome and that is why pain relief is an important aspect of parturition as painful labour has long term consequences on the labouring woman, her health and her well-being. ${ }^{6}$ 
Labour pain is a result of multiple psychological and physiological factors. It is a multi-dimensional framework. Pain generally is defined as having two basic components. A primary phenomenon consisting of afferent output from sensory receptors and a secondary phenomenon consisting of processing and reaction to the above signal. During the first stage of labour, the pain is mostly through the visceral pathway whereas in the second stage, it is mediated via both somatic and visceral pathways. ${ }^{7}$ There are a number of drugs which have been used for labour analgesia. In our observational study, we compared the efficacy of paracetamol and tramadol being used as labour analgesics in our institution.

Paracetamol is the most commonly used drug and considered as the first line of treatment for pain and hence is positioned as the first step of WHO recommended analgesic ladder. ${ }^{8}$ It acts by inhibiting cyclo-oxygenase (COX) and/or serotonergic system which thereby inhibits prostaglandin synthesis. It is effective, has good safety profile, is inexpensive and has few side effects.

Tramadol hydrochloride shares mechanisms of action of both opioids and tricyclic antidepressants, inhibits transmission of pain impulses, alters pain perception and reduces re-uptake of norepinephrine and serotonin in the descending spinal inhibitory system. It enhances effectiveness of inhibitory pathway, compared to other opioids, causes less maternal and foetal respiratory and cardiovascular depression. ${ }^{9}$ It is shown to be effective, well tolerated and placed as step 2 in WHO ladder of pain medications. ${ }^{10}$

Paracetamol is now being used as a labour analgesic in some institutions and there are studies which have compared paracetamol with tramadol in labour. However most of the articles reviewed have shown paracetamol being used intravenously and tramadol by intramuscular route. To cite a few, Das et al, Mohan et al and Lallar et al compared intravenous paracetamol and intramuscular tramadol for labour analgesia. ${ }^{11-13}$ In the present study both drugs had been used intravenously.

It has been observed in a study by Conell-Price et al that as the cervical dilatation increases during progression of labour, the pain experienced by the parturient also increases. ${ }^{14}$ In our study VAS score was calculated after each hour until 6 hours of administering the drug and it was found to be less in paracetamol group compared to tramadol group. Difference in VAS score at 1, 2, 3 and 6 hours was statistically insignificant. However, comparing the difference in VAS score at 4 and 5 hours, paracetamol showed statistically significant pain relief. The inference of this finding was that paracetamol provided better pain relief at a higher level of incremental contraction as the labour progressed. Though the overall difference of VAS scores between the two groups was not statistically significant, at a higher level of the labour trajectory, 4-5 hours phase of active labour, paracetamol showed a better effect.

Mohan et al and Lallar et al in their studies concluded that intravenous paracetamol is a more effective labour analgesic than intramuscular tramadol. ${ }^{11,13}$ However, Kaur et al opined that intravenous paracetamol provides comparable analgesia as intramuscular tramadol during active labour. ${ }^{15}$ Abhinaya et al conducted a study in 2017 comparing analgesic efficacy of both drugs in labouring women and found no difference in pain intensity before administration of drugs in both groups. ${ }^{16}$ However, there was significant pain reduction in paracetamol group compared to tramadol group after 1 hour and 3 hours of drug.

Table 7: Comparison of various other studies with present study according to route of administration.

\begin{tabular}{|c|c|c|c|c|c|}
\hline \multirow{2}{*}{ Author } & \multirow[t]{2}{*}{ Year } & \multicolumn{2}{|c|}{ Route of administration } & \multirow{2}{*}{ Result } & \multirow{2}{*}{ Remarks } \\
\hline & & Paracetamol & Tramadol & & \\
\hline Makkar et $a^{15}$ & 2014 & Intravenous & Intramuscular & Comparable efficacy in both & $\begin{array}{l}\text { Higher incidence of maternal } \\
\text { side effects with tramadol }\end{array}$ \\
\hline Lallar et al ${ }^{13}$ & 2014 & Intravenous & Intramuscular & $\begin{array}{l}\text { Paracetamol more effective } \\
\text { than tramadol }\end{array}$ & $\begin{array}{l}\text { Significant pain reduction in the } \\
\text { paracetamol group after } 1 \text { hour } \\
\text { and } 3 \text { hours of administration of } \\
\text { drug compared to tramadol } \\
\text { group }\end{array}$ \\
\hline Mohan et al ${ }^{12}$ & 2015 & Intravenous & Intramuscular & $\begin{array}{l}\text { Paracetamol more effective } \\
\text { than tramadol }\end{array}$ & $\begin{array}{l}\text { Maternal side effects higher in } \\
\text { tramadol group }\end{array}$ \\
\hline Abhinaya et al ${ }^{16}$ & 2015 & Intravenous & Intramuscular & $\begin{array}{l}\text { Comparable efficacy } \\
\text { immediately after } \\
\text { administration }\end{array}$ & \\
\hline Present study & 2018 & Intravenous & Intravenous & $\begin{array}{l}\text { Paracetamol was found to be } \\
\text { more effective than tramadol } \\
\text { at } 4^{\text {th }} \text { and } 5^{\text {th }} \text { hour but overall } \\
\text { efficacy was comparable }\end{array}$ & $\begin{array}{l}\text { Both drugs were given i.v. } \\
\text { paracetamol had fewer maternal } \\
\text { and neonatal side effects }\end{array}$ \\
\hline
\end{tabular}


In our study, the total duration of active phase of labour was slightly more in paracetamol group than the tramadol group; though the difference was statistically not significant.

The present study showed that birth weight of new-born did not have any significant bearing on analgesic efficacy of the drug. The neonatal outcome was found to be slightly more favourable with paracetamol than tramadol in our study. Babies born were assessed by attending paediatrician for any signs of respiratory distress like nasal flaring, grunting or intercostal retractions. $20 \%$ of babies born from mothers who received paracetamol were taken to NICU for minor respiratory problems compared to $30 \%$ in tramadol group. This showed that tramadol caused slightly more respiratory distress in the babies than paracetamol. However, neonatal distress was transient and all the babies were shifted back to the mother after a short duration of observation.

Some published studies concluded that the efficacy of intravenous paracetamol as a labour analgesic was higher than that of intramuscular tramadol (Table 7).

However in our study, where patients of both the groups received the drug intravenously, the overall analgesic efficacy levels were comparable with paracetamol having a significant edge at the height of labour progression.

The limitation of our study was that the sample size of the study was limited. Secondly, every patient reacts differently to pain. The character of the pain and its individual subjectivity are some of the variables which have not been taken into consideration.

\section{CONCLUSION}

Labour is an emotional experience and presents a psychological challenge to parturient due to the associated pain. Paracetamol and tramadol having advantage of easy availability, being relatively cheap with no special technique of administration were selected as labour analgesics for comparison in the present study. This study showed that paracetamol had a significantly better analgesic effect at the height of the labour graph, but the overall efficacy of both the drugs were comparable. Paracetamol also caused relatively less nausea and vomiting in the mother and less foetal distress in new-born. Thus paracetamol can be safely used as a labour analgesic.

\section{Funding: No funding sources}

Conflict of interest: None declared

Ethical approval: The study was approved by the Institutional Ethics Committee

\section{REFERENCES}

1. Mulder EJ, De Medina PR, Huizink AC, Van den Bergh BR, Buitelaar JK, Visser GH. Prenatal maternal stress: Effects on pregnancy and the (unborn) child. Early Hum Develop. 2002;70(1-2):314.

2. Brownridge $P$. The nature and consequences of childbirth pain. Eur J Obstet Gynecol Reprod Biol. 1995;59:S9-15.

3. Beilin Y. Advances in labor analgesia. Mount Sinai J Med. 2002;69(1-2):38-44.

4. Brown ST, Douglas C, Flood LP. Women's evaluation of intrapartum nonpharmacological pain relief methods used during labor. J Perinat Educ. 2001;10(3):1-8.

5. Block BM, Liu SS, Rowlingson AJ, Cowan AR, Cowan Jr JA, Wu CL. Efficacy of postoperative epidural analgesia: a meta-analysis. JAMA. 2003;290(18):2455-63.

6. Moore J. The effects of analgesia and anaesthesia on the maternal stress response. In: Effects on the baby of maternal analgesia and anaesthesia. WB Saunders: London; 1993:148-162.

7. Jarnbert-Pettersson H, Vixner L. Labour Q1 painpoorly analysed and reported: a systematic review. BMC Pregnanc Childbirth. 2018;18:483(1-9).

8. Sharma CV, Mehta V. Paracetamol: mechanisms and updates. Continuing Educ Anaesth Crit Care Pain J. 2014;14(4):153-8.

9. Patil S, Somashekara SC, Goud GKV, Bhanurekha S, Reddy LJ, Deepalaxmi S. Tramadol analgesia in labour. Int J Pharm Biomed Res. 2012;3(1):49-51.

10. Dayer P, Desmeules J, Collart L. Pharmacology of tramadol. Drugs 53 (1997):18-24. Obstet Gynecol Res Drugs. 1997;53(2):18-24.

11. Das BP, Ali J, Baruah A. Comparative study between intravenous paracetamol and intramuscular tramadol as labour analgesic. Int $\mathbf{J}$ Sci Res. 2016;5(10):1675-9.

12. Mohan H, Ramappa R, Sandesh M, Akash BK. Intravenous paracetamol infusion versus intramuscular tramadol as an intrapartum labor analgesic. Int J Reprod Contracept Obstet Gynecol. 2015;4(6):1726-9.

13. Lallar M, ul Haq A, Nandal R, Singh SP, Katyal S. Intravenous paracetamol infusion versus intramuscular tramadol as an intrapartum labor analgesic. J Obstet Gynaecol India. 2015;65(1):1722.

14. Conell-Price J, Evans JB, Hong D, Shafer S, Flood $\mathrm{P}$. The development and validation of a dynamic model to account for the progress of labor in the assessment of pain. Anesth Analg. 2008;106(5):1509-15.

15. Makkar JK, Jain K, Bhatia N, Jain V, Mithrawal SM. Comparison of analgesic efficacy of paracetamol and tramadol for pain relief in active labor. J Clin Anaesth. 2015;27(2):159-63.

16. Abhinaya A, Latha K, Jayashree V. Comparative study between intravenous paracetamol and intramuscular tramadol as labour analgesia. Int $\mathbf{J}$ Curr Med Pharm Res. 2017;3(10):2491-6. 
17. Abdollahi MH, Mojibian M, Pishgahi A, Mallah F, Dareshiri S, Mohammadi S, et al. Intravenous paracetamol versus intramuscular pethidine in relief of labour pain in primigravid women. Niger Med J. 2014;55(1): 54-7.

18. Andey AK, Aleenasibi, Ullagantisaichaitanya, Mohanta GP, Sangeereni M. Study on use of intramuscular tramadol as analgesic during labour. IOSR J Pharm Biol Sci. 2018;13(4):73-9.

Cite this article as: Viswanandh $\mathrm{P}$, Subramanian $\mathrm{S}$, Bal H. An observational study of parenteral paracetamol vis a vis tramadol as labour analgesics. Int J Reprod Contracept Obstet Gynecol 2021;10:677-82. 